\title{
Uncertainty Ontology for Module Rules Formation Waterwheel Control
}

\author{
Zulfian Azmi ${ }^{1}$, Mahyuddin K.M.Nasution ${ }^{2}$, Herman Mawengkang ${ }^{3}$, M.Zarlis ${ }^{4}$ \\ ${ }^{1}$ Postgraduate Doctoral Program of Computer Science, Universitas Sumatera Utara, Indonesia \\ ${ }^{2,3}$ Information Technology Departement, Universitas Sumatera Utara, Padang Bulan USU Medan, \\ Indonesia \\ Departement of Mathematics, Universitas Sumatera Utara, Padang Bulan USU Medan, Indonesia \\ Email: ${ }^{1}$ zulfian.azmi@gmail.com
}

\begin{abstract}
Implementation of Uncertainty model has not given maximum result in forming rule on an inference of a case. For testing to determine whether water quality is high, medium and low. The input variables used are temperature, $\mathrm{pH}$, salinity and Disolved Oxygen. Testing is done by looking at the water turbidity change in the shrimp pond, to determine the water quality. Its water quality determines in the control module of the waterwheel rotation.Rolling the waterwheel moves quickly if pond water quality is low, moving slowly if water quality is medium and immobile if water quality is good. And the establishment of the rule with the approach of knowledge of Ontology to determine the relation between several variables (temperature, $\mathrm{Ph}$, Disolved Oxygen and salinity). Each variable is set to its certainty value in the form of fuzzy value. Next is determined the relation of the four variables for the formation of rule.
\end{abstract}

Keywords: Neuron, Ontology, Uncertainty, Waterwheel

\section{INTRODUCTION}

Formation of rule based on variable input of temperature, $\mathrm{pH}$, salinity and Disolved Oxygen. Various input and linguistic input issues are important to be solved with uncertainty model [1]. It can also use the Fuzzy Set Mamdani (MFS) method to represent linguistic meaning in solving the given problem [2]. Also, Fuzzy Probalistic Expert System can be used for system training by using linguistic variables that can be understood by experts [3]. Furthermore, this model will be tested to determine the quality of water is good, medium and high with variable: Dissolved Oxigen, Temperature, salinity and water PH. And with that water quality determine the module konntrol whether the rotation of waterwheels move or not. And a combination of techniques drawn from fuzzy logic and neural networks can design a more effective control system. Choose a rule for Fuzzy Logic control that matches different environmental conditions. And to build a fuzzy-neural network system is designed a system that has an input-output relationship as a fuzzy reasoning unit [4]. And with the approach of ontology knowledge which is a philosophical study of the scientific nature of being, being, existence or reality as well as the basic categories of manifesting and its relationship. 


\section{METHODS}

\subsection{Ontology}

Ontology is a philosophical study of the scientific nature of being, becoming, excistence or reality as well as the basic categories of manifesting and relating. Ontology as a branch of philosophy refers to the reality around us, regardless of how our own view of it. Thus, an ontology requires one to make a firm distinction between the observing subject and the observed object. Ontology is often concerned with the concentrated question of whether whether an entity exists or is to be said to exist and how such entities can be grouped, related in levels, and divided according to similarities and differences [5].

\subsection{Mathematical Equations}

The Uncertainty Model is one of Fuzzy Logic which is the foundation that provides the high capability of the final computing with the related coordinated distributed resources and ensures the delivery of computing resources as expected. And its performance can be assessed in terms of different criteria that must be considered simultaneously in the scheduling process. Fuzzy Logic is a collection of phrases. arithmetic expressions allow mapping of inputs assigned to an output. involves components of variables, membership functions, Fuzzy Logic operators and "if-then" rules and when compared with conventional logic, the advantage of fuzzy logic is its ability to process reasoning in language so that in its design does not require complicated mathematical equations. Some of the reasons we can explain why we use fuzzy logic are easy to understand, tolerate improper data, capable of modeling very complex nonlinear functions, able to build and apply expert experiences directly without having to go through training process, able to cooperate with conventional control techniques, and based on natural language.

\section{RESULTS AND DISCUSSION}

\subsection{Input Data}

Based on PH relations, temperature, dissolved oxygen and salinity shown in Table 1. The larger the temperature the greater PH, Salinity and Dissolved Oxygen.

Table 1. The Relationship Between $\mathrm{PH}$ and Temperature

\begin{tabular}{cccc}
\hline $\begin{array}{c}\mathrm{X} 1 \\
\begin{array}{c}\text { Temperatu } \\
\left.\text { re/ }{ }^{\circ} \mathrm{C}\right)\end{array}\end{array}$ & $\begin{array}{c}\mathrm{Y} 1 \\
(\mathrm{DO}(\mathrm{mg} / \mathrm{l}))\end{array}$ & $\mathrm{Z1} \mathrm{( \textrm {PH } )}$ & $\begin{array}{c}\mathrm{W} 1 \\
\text { (Salinity) }\end{array}$ \\
\hline 0 & 14,62 & 7,5 & 34,9 \\
1 & 14,22 & 7,48 & 34,8 \\
2 & 13,83 & 7,46 & 34,7 \\
3 & 13,46 & 7,44 & 34,6 \\
4 & 13,11 & 7,42 & 34,5 \\
5 & 12,77 & 7,40 & 34,1 \\
6 & 12,45 & 7,38 & 34,2 \\
7 & 12,14 & 7,36 & 34,3 \\
8 & 11,84 & 7,34 & 34,2 \\
9 & 11,56 & 7,32 & 33,18 \\
10 & 11,29 & 7,30 & 33,16 \\
\hline
\end{tabular}




\begin{tabular}{lccc}
\hline 11 & 11,03 & 7,28 & 33,14 \\
12 & 10,78 & 7,26 & 34,1 \\
13 & 10,54 & 7,24 & 34,35 \\
14 & 10,31 & 7,22 & 34,6 \\
15 & 10,08 & 7,20 & 34,7 \\
16 & 9,87 & 7,18 & 34,8 \\
17 & 9,66 & 7,16 & 34,9 \\
18 & 9,47 & 7,14 & 35,0 \\
19 & 9,28 & 7,12 & 35,2 \\
20 & 9,09 & 7,10 & 35,2 \\
21 & 8,91 & 7,08 & 35,2 \\
22 & 8,74 & 7,06 & 35,1 \\
23 & 8,58 & 7,04 & 34,9 \\
24 & 8,42 & 7,03 & 35,1 \\
25 & 8,26 & 7,01 & 35,3 \\
26 & 8,11 & 7,01 & 35,4 \\
27 & 7,97 & 7,00 & 35.5 \\
28 & 7,83 & 6,69 & 35,6 \\
29 & 7,69 & 6,98 & 35,7 \\
30 & 7,56 & 6,97 & 35,8 \\
31 & 7,43 & 6,96 & 35,9 \\
32 & 7,30 & 6,96 & 4,00 \\
33 & 7,18 & 6,94 & 4,10 \\
34 & 7,06 & 6,94 & 4,20 \\
35 & 6,95 & 6,93 & 4,21 \\
36 & 6,84 & 6,91 & 4,22 \\
37 & 6,73 & 6,90 & 4,23 \\
38 & 6,62 & 6,90 & 4,24 \\
39 & 6,51 & 6,91 & 4,25 \\
40 & 6,2 & 6,92 & 4,26 \\
\hline
\end{tabular}

The degree of acidity $(\mathrm{pH})$ of water less than 6.5 or acidic $\mathrm{pH}$ increases corrosivity in metallic substances, causing discomfort and may cause some chemicals to be toxic to health and reference the results of testing color, temperature, mph and salinity (Fig.3.1). In the reference to the test results look water color with variable temperature, $\mathrm{pH}$ and salinity.

Table 2. Test results Color, temperature, $\mathrm{pH}$ and Salinity[6]

\begin{tabular}{ll}
\hline Criteria & Testing \\
\hline Color & Cloudy \\
Temperature $\left({ }^{0} \mathrm{C}\right)$ & 26 \\
pH & 7,6 \\
Salinity & 1,5 \\
Colour & Clear \\
Temperature $\left({ }^{\circ} \mathrm{C}\right)$ & 26 \\
pH & 7,4 \\
Salinity & 0,5 \\
\hline
\end{tabular}


From the results of this test can be taken linkage is that if the temperature (medium) and $\mathrm{PH}$ (base) and high salinity) so that the color change in turbid water means the water quality is not good. And if the temperature is (medium) and PH (neutral) and salinity (medium) so the color of clear water means the water quality is not good. One of the easiest indications to know the condition of water in aquaculture ponds is through water color changes pond water color should be taken at any time.

\subsection{Test Case}

Input data on square meter of pond from $4 \times 12$ matrix shown in Table 3.

Table 3. Water quality data of one shrimp pond in the village of Baru Tg.Ibus kec.Stabat.

\begin{tabular}{ccccc}
\hline No & $\begin{array}{c}\mathrm{X} 1 \\
\text { (Temperature/oC) }\end{array}$ & Y1 (DO $(\mathrm{mg} / \mathrm{l}))$ & $\mathrm{Z1}(\mathrm{PH})$ & $\begin{array}{c}\mathrm{W} 1 \\
\text { (Salinity) }\end{array}$ \\
\hline 1 & 20 & 9,09 & 7,10 & 35,2 \\
2 & 21 & 8,91 & 7,08 & 35,2 \\
3 & 22 & 8,74 & 7,06 & 35,1 \\
4 & 23 & 8,58 & 7,04 & 34,9 \\
5 & 24 & 8,42 & 7,03 & 35,1 \\
6 & 25 & 8,26 & 7,01 & 35,3 \\
7 & 26 & 8,11 & 7,01 & 35,4 \\
8 & 27 & 7,97 & 7,00 & 35,5 \\
9 & 28 & 7,83 & 6,69 & 35,6 \\
10 & 29 & 7,69 & 6,98 & 35,7 \\
11 & 30 & 7,56 & 6,97 & 35,8 \\
12 & 31 & 7,43 & 6,96 & 35,9 \\
\hline
\end{tabular}

\subsection{Degree of Membership}

\section{a. Degree of Membership PH}

The curve for degree of membership $(\mu)$ in the variable PH consists of three fuzzy sets namely Acid, Basa, Neutral.

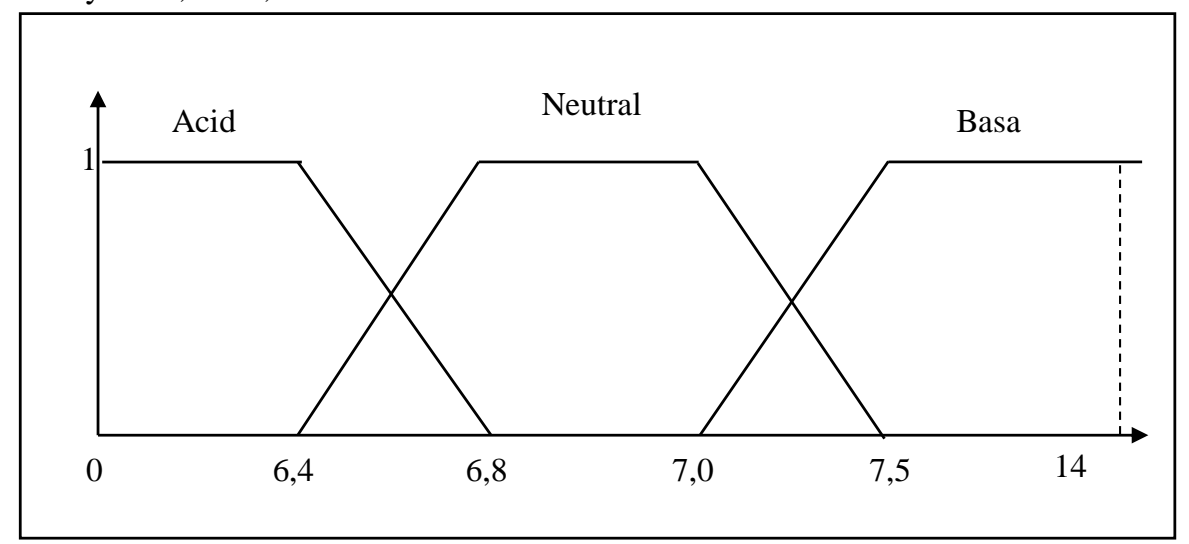

Figure 1. Degree of Sensor Membership PH 
The degree of acidity of a substance $(\mathrm{pH})$ is shown on a scale of $0-14$.

- Solutions with $\mathrm{pH}(0-6,4)$ are acid.

- Solutions with a $\mathrm{pH}(6.5-7.5)$ are neutral.

- Solutions with pH (7,6-14) are Basa.

The value of $\mathrm{PH}$ water membership:

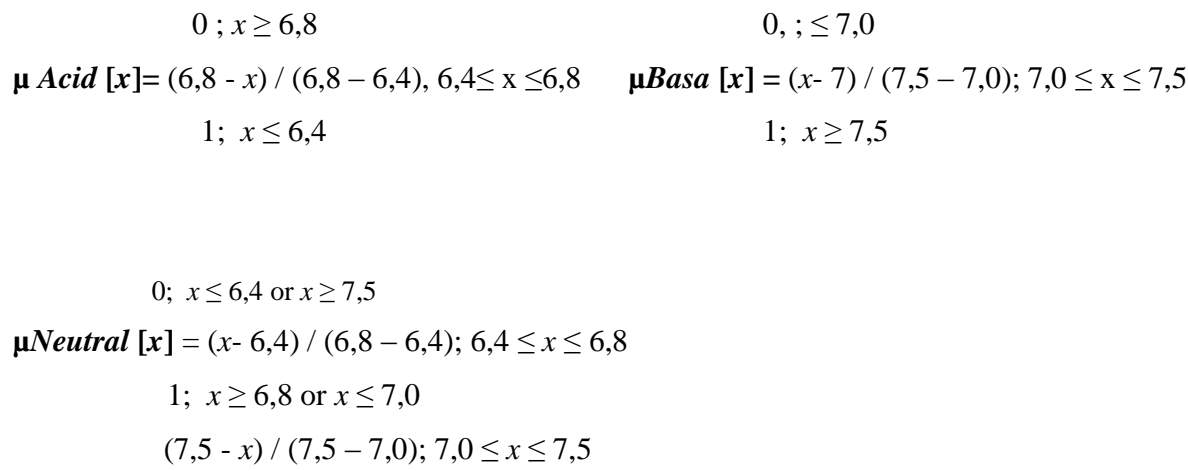

\section{b. Degree of Temperature Membership}

The curve for degrees of membership $(\mu)$ in the temperature variable consists of three fuzzy sets of heat, medium, cold.

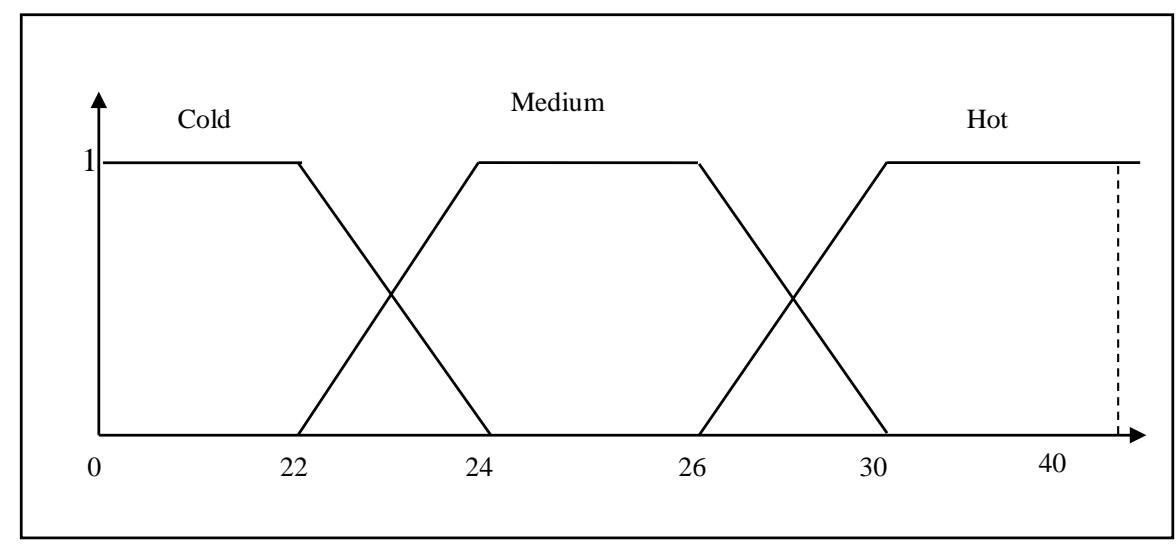

Figure 2. Degree of Temperature membership

The value of Temperature membership:

$$
0 ; x \geq 22 \quad 0, ; \leq 26
$$

$\mu$ Cold $[x]=(24-x) /(24-22), 22 \leq \mathrm{x} \leq 24$

$\boldsymbol{\mu H o t}[\boldsymbol{x}]=(x-26) /(30-26) ; 26 \leq \mathrm{x} \leq 30$

$$
1 ; x \leq 24
$$$$
1 ; x \geq 30
$$

$0 ; x \leq 22$ or $x \geq 30$ 
$\boldsymbol{\mu M e d i u m}[\boldsymbol{x}]=(x-22) /(24-22) ; 22 \leq x \leq 24$

$$
\begin{aligned}
& 1 ; x \geq 24 \text { or } x \leq 26 \\
& (30-x) /(30-26) ; 26 \leq x \leq 30
\end{aligned}
$$

\section{c. The Value of Salinity Membership}

The curve for degree of membership $(\mu)$ in the variable consists of three fuzzy sets ie low, medium, high.

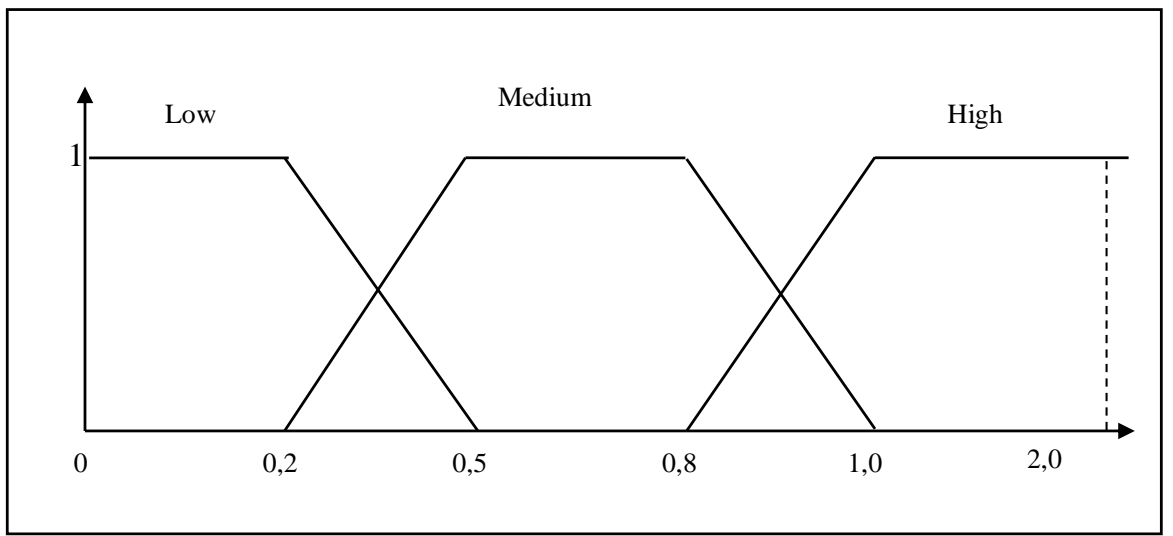

Figure 3. The Value of Salinity Membership

The value of Salinity membership:

$0 ; x \geq 0,2$

$\boldsymbol{\mu} \operatorname{Low}[x]=(0,5-x) /(0,5-0,2), 0,2 \leq \mathrm{x} \leq 0,5 \quad \boldsymbol{\mu H} \boldsymbol{H i g h}[\boldsymbol{x}]=(x-0,8) /(1,0-0,8) ; 0,8 \leq \mathrm{x} \leq 1,0$

$1 ; x \leq 0,5 \quad 1 ; x \geq 1,0$

$0 ; x \leq 6,4$ or $x \geq 7,5$

HMedium $[x]=(x-22) /(24-22) ; 22 \leq x \leq 24$

$1 ; x \geq 24$ or $x \leq 26$

$(30-x) /(30-26) ; 26 \leq x \leq 30$ 


\section{d. Degree of Membership of Disolved Oxygen}

The curve for degree of membership $(\mu)$ on the variable consists of three fuzzy sets ie small, medium, large.

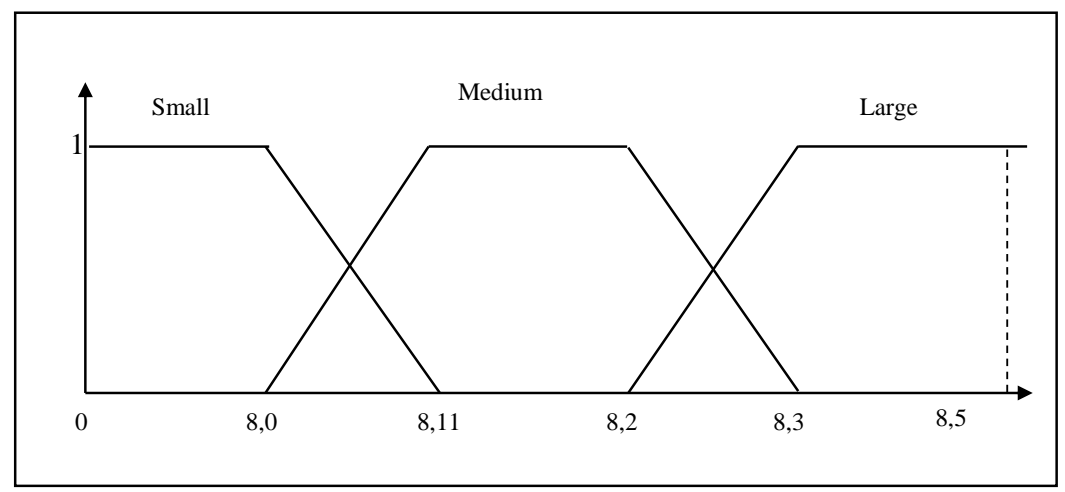

Figure 4. Degree of Membership of Disolved Oxygen

The value of Salinity membership:

$$
0 ; x>8,0 \quad 0 ; \leq 8,3
$$

$\boldsymbol{\mu}$ Small $[x]=(8,11-x) /(8,11-8,0), 8,0 \leq \mathrm{x} \leq 8,11$

$\boldsymbol{\mu} \operatorname{Large}[x]=(x-8,2) /(8,3-8,2) ; 8,2 \leq \mathrm{x} \leq 8,3$

$$
1 ; x \leq 8,0
$$

$1 ; x \geq 8,3$

$$
0 ; x \leq 8,0 \text { or } x \geq 8,3
$$

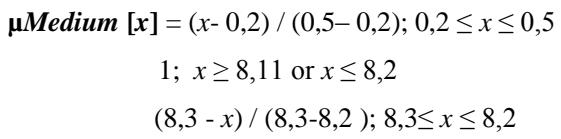

Furthermore, based on water PH criteria, temperature, salinity and dissolved oxygen for input matrix using with Fuzzy value. The formation of the rule as a determination of rules and didefuzzifikasikan to make a numerical output. Fuzzification is the process by which the input data of a fixed value (input crips) into a fuzzy input. The variables used are temperature, disooved oxygen, ph and salinity. From the results of this test can be taken linkage that if the temperature (medium) and $\mathrm{PH}$ (base) and high salinity) so that the color of turbid water means the quality of water is not good. And the waterwheel round does not move. And if the temperature is (medium) and $\mathrm{PH}$ (neutral) and salinity (medium) so the color of clear water means good water quality. And round the waterwheel move. So, the formation of rules of these variables are as follows:

Rule:

1. IF PH Acid AND Cold Temperature AND Low Salinity and Dissolved Small Oxygen THEN Low Water Quality AND Swivel Waterwheel Moving. 
2. IF PH neutral AND Temperature medium AND Salinity medium AND Disolved Oxygen medium THEN Medium Water Quality AND Slipper Slope Moves Slow.

3. IF PH alkaline AND Temperature medium AND Salinity medium AND Disolved Oxygen medium THEN Low Water Quality AND Range of Waterwheel Moves.

4. IF PH alkaline AND Hot temperature AND Salinity medium AND Disolved Oxygen medium THEN Low Water Quality AND Swivel Waterwheel Moving.

5. IF PH base AND Heat temperature AND Salinity a lot AND Disolved Oxygen medium THEN Low Water Quality AND Fingerless Waterwheel Round.

6. IF PH alkaline AND Heat temperature AND Salinity many AND Disolved Oxygen medium THEN Low Water Quality AND Swivel Waterwheel Moving.

7. IF PH alkaline AND Heat temperature AND High salinity AND Disolved Oxygen ManyTHEN Low Water Quality AND Round Waterwheel Moving

8. IF PH neutral AND Heat temperature AND High salinity AND Disolved Oxygen ManyTHEN Water Quality Low AND Round Waterwheel Moving

9. IF PH neutral AND Neutral Temperature AND High salinity AND Disolved Oxygen Many THEN Low Water Quality AND Swivel Waterwheel Moving

10. IF PH neutral AND Neutral temperature AND Neutral salinity AND Disolved Oxygen LOT THEN Low Water Quality AND Round Waterwheel Moving

11. IF PH neutral AND Neutral Temperature AND Neutral Salinity and Disolved Oxygen Many THEN Good Water QualityAND Revolving Waterwheel Round

12. IF PH neutral AND Thermal temperature AND Neutral Salinity and Disolved Oxygen Many THEN Low Water Quality AND Round of Waterwheel Moving

13. IF PH neutral AND Heat temperature AND High salinity AND Disolved Oxygen LOT THEN Low Water Quality AND Round Waterwheel Moving

14. IF PH neutral AND Heat temperature AND High salinity AND Disolved Oxygen being THEN Low Water Quality AND Swivel Waterwheel Moving

15. IF PH base AND Heat temperature AND High salinity AND Disolved Oxygen being THEN Low Water Quality AND Swivel Waterwheel Moving.

\section{CONCLUSION}

Ontology be knowledge modeling to find relation and relationship between knowledge of shrimp culture with the formation of rule on windmill module. The change of water turbidity color is part to know the water quality at farm ponds. Rolling the waterwheel moves quickly if the water quality of the pond is tough, moving slowly if the water quality is medium and does not move if the water quality is good.

\section{REFERENCES}

[1] Zhang, D., \& Pal, S. K. (2000). A Fuzzy Clustering Neural Networks (Fens) System Design Methodology. IEEE Transactions on Neural Networks, 11(5), 1174-1177.

[2] Asadi, M. (2016). Optimized Mamdani fuzzy models for predicting the strength of intact rocks and anisotropic rock masses. Journal of Rock Mechanics and Geotechnical Engineering, 8(2), 218-224.

[3] Amiri, M., Ardeshir, A., \& Zarandi, M. H. F. (2017). Fuzzy Probabilistic Expert System for Occupational Hazard Assessment in Construction. Safety Science, 93, 16-28. 
[4] Huang, S. H. (1994). Advanced Fuzzy Logic Controllers and Self-Tuning Strategy. Owa State University, Digital Repository @ Iowa State University.

[5] Nasution, M. K. (2012). Kolmogorov Complexity: Clustering objects and similarity, Buletin of Mathematic 3(1):1-16.

[6] Harianti, H., \& Nurasia, N. (2016). Analisis Warna, Suhu, PH dan Salinitas Air Sumur Bor Di Kota Palopo. Prosiding Seminar Nasional, 2(1): 747-753. 